\title{
PTEN expression and mutation in colorectal carcinomas
}

\author{
XIAO-HAN LI ${ }^{1,2^{*}}$, HUA-CHUAN ZHENG ${ }^{1,3^{*}}$, HIROYUKI TAKAHASHI ${ }^{1}$, \\ SHINJI MASUDA ${ }^{4}$, XIANG-HONG YANG ${ }^{2}$ and YASUO TAKANO ${ }^{1}$
}

\begin{abstract}
${ }^{1}$ Department of Diagnostic Pathology, Graduate School of Medicine and Pharmaceutical Science, University of Toyama, Sugitani 2630, Toyama, Japan; ${ }^{2}$ Division of Pathology, Affiliated Shengjing Hospital of China Medical University, Shenyang; ${ }^{3}$ Department of Biochemistry and Molecular Biology, College of Basic Medicine, China Medical University, Shenyang, P.R. China; ${ }^{4}$ Division of Pathology, Kouseiren Takaoka Hospital, Takaoka, Japan
\end{abstract}

Received December 19, 2008; Accepted April 6, 2009

DOI: $10.3892 /$ or_00000497

\begin{abstract}
The phosphatase and tensin homolog deleted on chromosome 10 (PTEN) tumor suppressor is a phosphatase that antagonizes the phosphoinositol-3-kinase/AKT signaling pathway and suppresses cell survival as well as cell proliferation. To investigate the molecular role of PTEN expression and mutation in colorectal carcinomas, we performed immunohistochemistry to detect PTEN expression on tissue microarray containing colorectal carcinomas and corresponding adjacent non-cancerous mucosa. PTEN mutation was studied from exon 1 to 9 by PCR, followed by direct sequencing. PTEN expression was then compared with clinicopathological parameters and prognosis of the tumor, including caspase- 3 expression. In the present study, PTEN expression was stronger in the adjacent non-cancerous mucosa than carcinoma $(\mathrm{P}<0.001)$. Low PTEN expression was positively correlated with tumor size, depth of invasion, lymphatic invasion, lymph node metastasis, higher Dukes staging and reduced caspase- 3 expression $(\mathrm{P}<0.05)$, but not with venous invasion or differentiation $(\mathrm{P}>0.05)$. Univariate analysis suggested that the patients without PTEN expression had shorter survival than the patients with its expression $(\mathrm{P}=0.003)$. Multivariate analysis indicated that lymphatic invasion, venous invasion, and PTEN expression were independent prognostic factors for overall colorectal carcinomas $(\mathrm{P}<0.05)$. The analysis of mutations revealed only one synonymous mutation in exon 8 (codon 312 Asp: $\mathrm{GAC} \rightarrow \mathrm{GAT})$. These results suggested that down-regulated
\end{abstract}

Correspondence to: Dr Hua-Chuan Zheng, Department of Diagnostic Pathology, Graduate School of Medicine and Pharmaceutical Science, University of Toyama, Sugitani 2630, Toyama, Japan

E-mail: zheng_huachuan@hotmail.com

*Contributed equally

Key words: colorectal carcinoma, PTEN, pathobiological behavior, prognosis
PTEN expression was involved in the pathogenesis, invasion and metastasis of colorectal carcinomas possibly by regulating the balance between apoptosis and proliferation. PTEN expression may be a good marker for the prognosis of colorectal carcinoma.

\section{Introduction}

Malignant transformation is a biologically complicated process, including the activation of oncogenes and the inactivation of tumor suppressor genes (TSG), which in turn relieves cells from the balance between proliferation and apoptosis to promote tumor development (1). Among genetic changes in malignancies, chromosomal deletion, which could lead to loss of TSG causing uncontrolled proliferation and immortal survival, always provides some new insights into identification of genes critical for initiation, promotion and development of tumor, like PTEN (2).

PTEN gene (phosphatase and tensin homology deleted from human chromosome 10), also referred to as MMAC1 (mutated in multiple advanced cancers) or TEP-1 (TGF-ßregulated and epithelial cell-enriched phosphatase) is located on human chromosome 10q23.3 and contains nine exons and encodes a $47 \mathrm{kd}$ dual specific protein-phospholipid phosphatase with 403 amino acids (1). Structurally, PTEN is comprised of three parts: i) a 185-amino acid $\mathrm{NH}_{2}$-teminal phosphatase catalytic domain with high sequence homology to the cytoskeleton protein chicken tensin and bovine auxilin; ii) a $\mathrm{COOH}$-terminal $\mathrm{C} 2$ domain; iii) a 50-amino acid $\mathrm{COOH}$ terminal tail with PDZ binding motif and CK2 (formerly casein kinase II) phosphorylation sites. Functionally, it could inhibit shc (src-homology collagen) phosphorylation and therefore blocks the activation of the Ras/MAP-kinase pathway. PTEN also dephosphorylated focal adhesion kinase (FAK), affecting cell adhesion, spreading and recognition. Furthermore, PTEN acts as a phospholipid phosphatase with phosphatidylinosiol 3, 4, 5-triphosphate $\left(\mathrm{PIP}_{3}\right)$ as a substrate and one downstream target of $\mathrm{PIP}_{3}$, protein kinase (Akt/PKB), is continually activated by phosphorylation in cells lacking in functional PTEN (3). Jones et al (4) found that activation of PTEN signal pathway could target activation of CPP (cysteine protease protein)-32, resulting in inhibition of cellular apoptosis. These findings suggest 

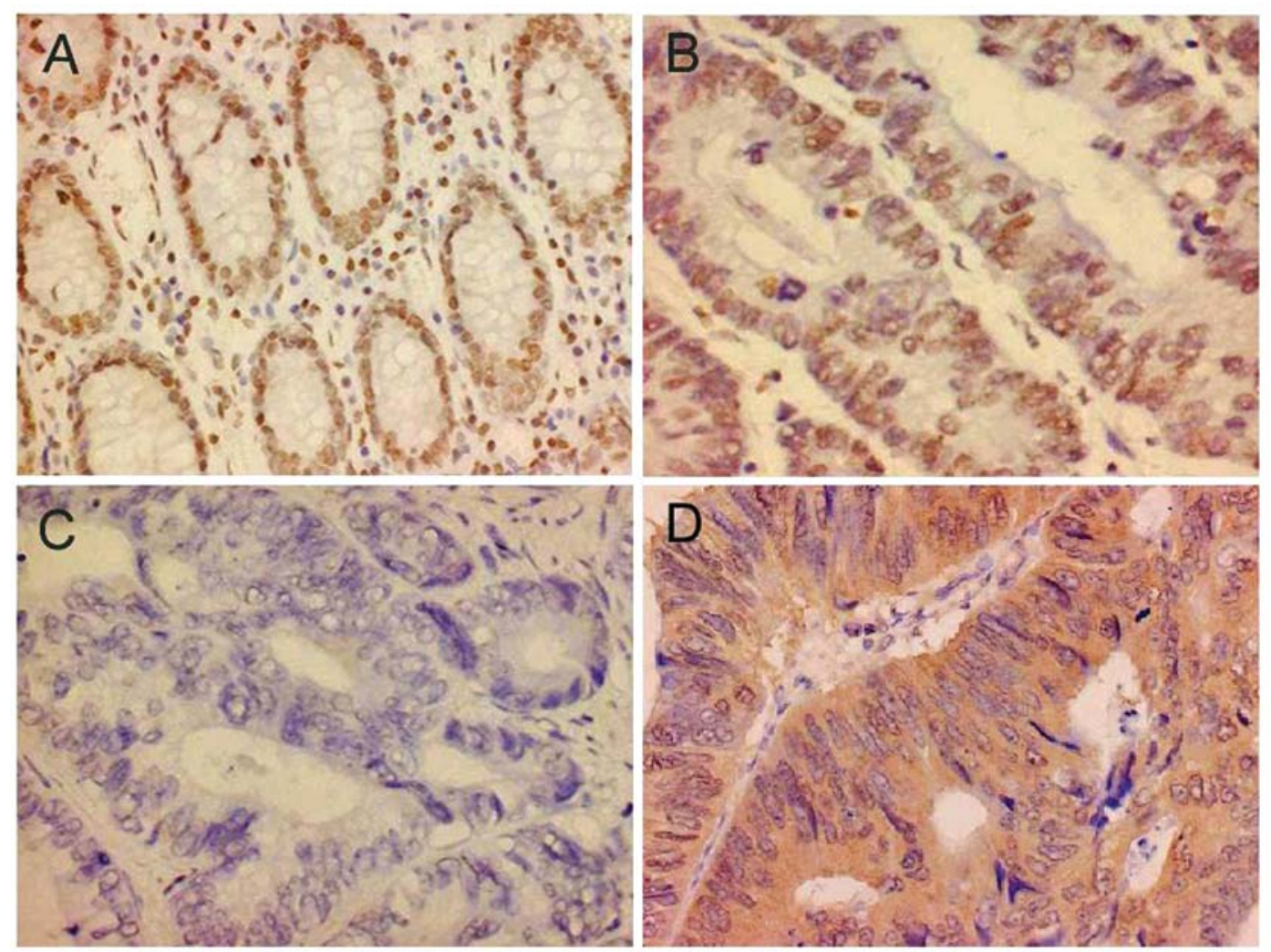

Figure 1. Immunohistochemical staining of colorectal samples. PTEN was positively expressed in the nucleus of the adjacent non-cancerous mucosa (a) and colorectal carcinomas (b). In some cancerous cases, no PTEN expression was detected (c). Caspase-3 was distributed in the cytoplasm of the carcinoma (d).

PTEN plays an essential role in tumorigenesis and progression of maligancies as a TSG.

PTEN gene was found to be one of the most commonly mutated tumor suppressors in human malignancies (5). The hereditary loss of PTEN leads to numerous autosomal dominant disorders: Cowden syndrome, Bannayan-RileyRuvalcaba syndrome, Lhermitte-Duclos disease, Proteus syndrome and Proteus-like syndrome, which are characterized by the presence of developmental defects, benign hamartomas and an increased risk of cancer (6-9). Genetic alterations of the PTEN gene range from point mutations to large chromosomal deletions (10-12). The mutation of PTEN is regularly observed in a considerable fraction of malignancies, such as breast, prostate, colon, endometrial and ovarian carcinomas (13-16).

Colorectal cancer is an important public health problem: there are nearly one million new cases of colorectal cancer diagnosed worldwide each year and half a million deaths. Japan has experienced a marked increase in the incidence of colorectal cancer, and was recently listed in the group of countries with the world's highest incidence rates $(17,18)$. Therefore, we studied the PTEN expression and mutation in Japanese colorectal cancer to clarify the molecular effect of PTEN alteration on the multistep development of colorectal carcinomas.

\section{Materials and methods}

Subjects. Three hundred and twenty-seven cases of formalinfixed and paraffin-embedded colorectal carcinomas and non- cancerous mucosa specimens were collected in Division of Pathology, Takaoka Kouseiren Hospital from 1993 to 2002. The patients with colorectal carcinomas were 184 men and 143 women (18-90 years, mean, 69.16 years). In 128 cases, tumor development was accompanied with lymph node metastasis. None of the patients underwent chemotherapy or radiotherapy before surgery. All provided consent for use of tumor tissue for clinical research and our University Ethics Committee approved the research protocol. Two hundred and seventy-nine cases were followed up by consulting their case documents and telephoning.

Pathology. All tissues were fixed in $10 \%$ neutralized formalin, embedded in paraffin and cut into $4 \mu \mathrm{m}$ sections stained with hematoxylin and eosin (HE) to confirm the histological diagnosis and microscopic characteristics. The staging for each colorectal carcinoma was evaluated according to the Dukes staging system indicating the extent of tumor spread (19). Furthermore, tumor size, depth of invasion, lymphatic and venous invasion, and lymph node metastasis of tumors were determined.

Tissue microarray (TMA) and immunohistochemistry. From HE stained sections of the selected tumor cases, representative areas of solid tumor were selected for sampling and 4-mm diameter tissue cores per donor block were punched out and transferred to a recipient block with a maximum 24 cores using a Tissue Microarrayer (Azumaya Kin-1, Japan). Thick sections ( $4 \mu \mathrm{m})$ were consecutively cut from the microarrays and transferred to polylysine-coated glass 
Table I. Oligonucleotide primers used in mutation screen of PTEN.

\begin{tabular}{|c|c|c|c|c|}
\hline Exon & Primer sequences & Distribution (GI:4240386) & $\operatorname{AT}\left({ }^{\circ} \mathrm{C}\right)$ & Product size (bp) \\
\hline 1 & $\begin{array}{l}\text { Forward: 5'-CTCCTCCTTTTTCTTCAGCC-3' } \\
\text { Reverse: 5'-TATGACCTAGCAACCTGACCA-3' }\end{array}$ & $\begin{array}{l}23305-23324 \\
23527-23547\end{array}$ & 56 & 243 \\
\hline 3 & $\begin{array}{l}\text { Forward: 5'-ATAGAAGGGGTATTTGTTGGA-3' } \\
\text { Reverse: 5'-ACCTCACTCTAACAAGCAGATA-3' }\end{array}$ & $\begin{array}{l}83319-83339 \\
83590-83611\end{array}$ & 56 & 293 \\
\hline 4 & $\begin{array}{l}\text { Forward: 5'-TTCAGGCAATGTTTGTTA-3' } \\
\text { Reverse: 5'-CTCGATAATCTGGATGACTCA-3' }\end{array}$ & $\begin{array}{l}88928-88945 \\
89132-89152\end{array}$ & 48 & 225 \\
\hline 5 & $\begin{array}{l}\text { Forward: 5'-GCAACATTTCTAAAGTTACCTA-3' } \\
\text { Reverse: 5'-TCTGTTTTCCAATAAATTCTC-3' }\end{array}$ & $\begin{array}{l}90904-90925 \\
91269-91289\end{array}$ & 48 & 386 \\
\hline 6 & $\begin{array}{l}\text { Forward: 5'-GAGTAACTATTCCCAGTCAGA-3' } \\
\text { Reverse: 5'-TAATTTGTTCAAATGCTTCAGA-3' }\end{array}$ & $\begin{array}{l}110087-110107 \\
110351-110372\end{array}$ & 52 & 286 \\
\hline 7 & $\begin{array}{l}\text { Forward: 5'-ATCGTTTTTGACAGTTTG-3' } \\
\text { Reverse: 5'-CCAATGAAAGTAAAGTACA-3' }\end{array}$ & $\begin{array}{c}115750-115767 \\
15991-116009\end{array}$ & 48 & 260 \\
\hline 8 & $\begin{array}{l}\text { Forward: 5'-AGGTGACAGATTTTCTTTTTTA-3' } \\
\text { Reverse: 5'-TCAGCTGTACTCCTAGAATTA-3' }\end{array}$ & $\begin{array}{l}118771-118792 \\
119145-119165\end{array}$ & 52 & 394 \\
\hline 9 & $\begin{array}{l}\text { Forward: 5'-GTTCATCTGCAAAATGGA-3' } \\
\text { Reverse: 5'-TGGTAATCTGACACAATGTCCTA-3' }\end{array}$ & $\begin{array}{l}123153-123170 \\
123527-123549\end{array}$ & 50 & 397 \\
\hline
\end{tabular}

AT, annealing temperature.

slides. HE staining was performed for confirmation of tumor tissue (Fig. 1A).

Serial sections of TMA were deparaffinized with xylene, dehydrated with alcohol, and subjected to immunohistochemical staining with intermittent microwave radiation as previously described (20). Mouse anti-human PTEN (1:150, NovoCastra, UK) and rabbit anti-human caspase-3 (1:150, Dako, USA) antibodies were used to detect the respective proteins, with Envision+ system labeled polymer-HRP antimouse IgG or anti-rabbit IgG (Dako) as the secondary antibody. Binding was visualized with 3,3'-diaminobenzidine (DAB) and counterstaining with Mayer's hematoxylin was performed to aid orientation. Omission of the primary antibody was used as a negative control.

The immunoreactivity for PTEN was localized in the nucleus, while caspase-3 in the cytoplasm (Fig. 1). One hundred cells were randomly selected and counted from five representative fields of each section blindly by three independent observers (Takano Y., Zheng H.C. and Li X.H.) and the percentage of positive cells in the total counted was graded semi-quantitatively using a four-tier scoring system: negative (-), 0-5\%; weakly positive $(+), 6-25 \%$; moderately positive $(++), 26-50 \%$; and strongly positive $(+++), 51-100 \%$.

DNA extraction and checking. Fifty-seven cancer samples were randomly selected for the detection of PTEN mutation. Paraffin-embedded blocks were sectioned at $10 \mu \mathrm{m}$ and cancer lesions on slides were microdissected with reference to $\mathrm{HE}$ staining of consecutive sections, and subject to deparaffinization. DNA was extracted from the deparaffinized samples by standard proteinase $\mathrm{K}$ digestion and phenol/ chloroform extraction. All the DNA samples were amplified using B-globin primers, sense: 5'-ACACAACTGTG TTCACTAGC-3' and anti-sense: 5'-GTCTCCTTAAACC TGTCTTG-3' (175 bp) by 30 cycles of denaturation at $95^{\circ} \mathrm{C}$ for $30 \mathrm{sec}$, annealing at $55^{\circ} \mathrm{C}$ for $30 \mathrm{sec}$, and extension at $72^{\circ} \mathrm{C}$ for $30 \mathrm{sec}$ to confirm their integrity.

PCR. PCR amplification was performed using three individual sets of primers for exons 1-9 of PTEN as described in Table I containing their distribution, annealing temperatures, extension time and amplicon size. Twenty-five microliter of reaction mixtures contained $0.125 \mu 1$ Takara Ex Taq HS (Takara, Japan) and $0.02 \mu 1$ PfuUltra Highfidelity DNA polymerase (Stratagene, USA) with $2.0 \mathrm{mM}$ $\mathrm{MgCl}_{2}, 2.5 \mu 1$ 10X PCR buffer, $2.5 \mu 1 \mathrm{dNTP}$ mixture, $1 \mu \mathrm{M}$ of each primer set (external primers), and $250 \mathrm{ng}$ of template DNA. PCR conditions were denaturation at $95^{\circ} \mathrm{C}$ for $10 \mathrm{~min}$, followed by 30 cycles of denaturation at $95^{\circ} \mathrm{C}$ for $15 \mathrm{sec}$, annealing for $30 \mathrm{sec}$, and extension at $72^{\circ} \mathrm{C}$. As a termination step, the extension time of the last cycle was increased to 7 min. Sample amplified in the absence of template DNA was employed as negative controls.

DNA direct sequencing. Amplicons were purified with MicroSpin SR-300 columns (Amersham Biosciences, UK). After extraction, the DNA was quantified by Nanodrop ND-100 Spetrophotometer (Laboratory \& Medical Supplies, Japan) and then sequenced using a BigDye Terminator v3.1 cycle sequencing kit (Applied Biosystems, USA) with each 
Table II. PTEN expression in colorectal carcinomas and corresponding adjacent non-cancerous mucosa.

\begin{tabular}{lcrrrrrr}
\hline & & \multicolumn{5}{c}{ PTEN expression } \\
\cline { 3 - 8 } Groups & $\mathrm{n}$ & - & + & ++ & +++ & PR $(\%)$ & P-value \\
\hline Non-cancerous mucosa & 327 & 2 & 52 & 145 & 127 & 99.4 & $<0.001$ \\
Carcinomas & 327 & 95 & 93 & 87 & 52 & 70.9 & \\
\hline
\end{tabular}

PR, positive rate.

Table III. Relationship between PTEN expression and clinicopathological features of colorectal carcinomas.

\begin{tabular}{|c|c|c|c|c|c|c|c|}
\hline \multirow{2}{*}{$\begin{array}{l}\text { Clinicopathological } \\
\text { features }\end{array}$} & \multirow[b]{2}{*}{$\mathrm{n}$} & \multicolumn{6}{|c|}{ PTEN expression } \\
\hline & & - & + & ++ & +++ & $\mathrm{PR}(\%)$ & P-value \\
\hline Age (years) & & & & & & & 0.472 \\
\hline$<65$ & 123 & 32 & 37 & 33 & 21 & 74.0 & \\
\hline$\geq 65$ & 204 & 63 & 56 & 54 & 31 & 69.1 & \\
\hline Gender & & & & & & & 0.049 \\
\hline Male & 184 & 49 & 48 & 52 & 35 & 73.4 & \\
\hline Female & 143 & 46 & 45 & 35 & 17 & 67.8 & \\
\hline Tumor size (cm) & & & & & & & 0.022 \\
\hline$\leq 5$ & 211 & 47 & 64 & 60 & 40 & 77.7 & \\
\hline$>5$ & 116 & 48 & 29 & 27 & 12 & 58.6 & \\
\hline Depth of invasion & & & & & & & 0.000 \\
\hline $\mathrm{T}_{\mathrm{is}}-\mathrm{T}_{1}$ & 32 & 4 & 7 & 10 & 11 & 87.5 & \\
\hline $\mathrm{T}_{2}-\mathrm{T}_{4}$ & 295 & 91 & 86 & 77 & 41 & 69.2 & \\
\hline Differentiation & & & & & & & 0.093 \\
\hline Well-differentiated & 165 & 42 & 47 & 49 & 27 & 74.5 & \\
\hline Moderately differentiated & 148 & 46 & 41 & 38 & 23 & 68.9 & \\
\hline Poorly differentiated & 14 & 7 & 5 & 0 & 2 & 50.0 & \\
\hline Lymphatic invasion & & & & & & & 0.033 \\
\hline- & 233 & 62 & 64 & 65 & 42 & 73.4 & \\
\hline+ & 94 & 33 & 29 & 22 & 10 & 64.9 & \\
\hline Venous invasion & & & & & & & 0.091 \\
\hline- & 278 & 75 & 82 & 76 & 45 & 73.0 & \\
\hline+ & 49 & 20 & 11 & 11 & 7 & 59.2 & \\
\hline Lymph node metastasis & & & & & & & 0.012 \\
\hline- & 199 & 48 & 55 & 62 & 34 & 75.9 & \\
\hline+ & 128 & 47 & 38 & 25 & 18 & 63.3 & \\
\hline Dukes staging & & & & & & & 0.011 \\
\hline$A+B$ & 199 & 49 & 54 & 61 & 35 & 75.4 & \\
\hline $\mathrm{C}$ & 128 & 46 & 39 & 26 & 17 & 64.1 & \\
\hline Caspase-3 expression & & & & & & & $<0.001$ \\
\hline- & 82 & 37 & 21 & 12 & 12 & 54.9 & \\
\hline$+\sim+++$ & 245 & 58 & 72 & 75 & 40 & 76.3 & \\
\hline
\end{tabular}

PR, positive rate; $\mathrm{T}_{\text {is }}$, carcinoma in situ; $\mathrm{T}_{1}$, lamina propria and submucosa; $\mathrm{T}_{2}$, muscularis propria and subserosa; $\mathrm{T}_{3}$, exposure to serosa; $\mathrm{T}_{4}$, invasion into serosa. 
Table IV. PTEN mutation screening in colorectal carcinomas.

\begin{tabular}{llccc}
\hline Exon & $\mathrm{n}$ & Amplification no. $(\%)$ & DNA sequencing no. (\%) & Mutation no. (\%) \\
\hline 1 & 57 & $52(91.2)$ & $43(75.4)$ & 0 \\
3 & 57 & $21(36.8)$ & $14(24.6)$ & 0 \\
4 & 57 & $32(56.1)$ & $20(35.1)$ & 0 \\
5 & 57 & $16(28.1)$ & $12(21.1)$ & 0 \\
6 & 57 & $26(45.6)$ & $14(24.6)$ & 0 \\
7 & 57 & $35(61.4)$ & $32(56.1)$ & $1(1.8)$ \\
8 & 57 & $10(17.5)$ & $8(14)$ & 0 \\
9 & 57 & $10(17.5)$ & $8(14)$ & 0 \\
\hline
\end{tabular}

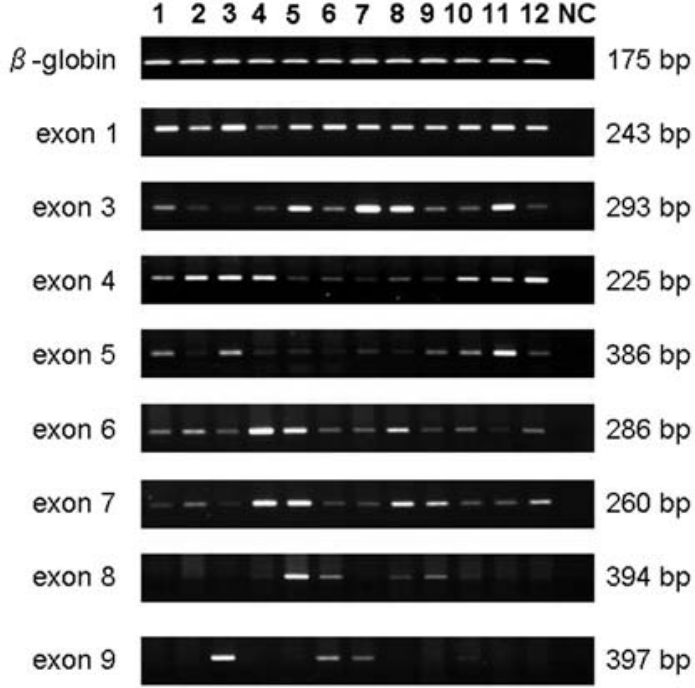

NC: negative control

Figure 2. Detection of $\beta$-globin and PTEN in colorectal carcinomas ß-globin was positive in all cases of colorectal carcinomas. Exons 1, 3-9 of PTEN were positive in some carcinoma cases by PCR. NC, negative control.

pair of forward and reverse primers. The sequence data were compared with PTEN sequence (Genbank GI: 4240386) using BLAST.

Statistical analysis. Statistical evaluation was performed using the Spearman correlation test to analyze rank data. KaplanMeier survival plots were generated and comparisons between survival curves were made with the log-rank statistic. The Cox's proportional hazards model was employed for multivariate analysis. $\mathrm{P}<0.05$ was considered as statistically significant. SPSS 10.0 software was employed to analyze the data.

\section{Results}

Expression of PTEN in corresponding non-cancerous mucosa and colorectal carcinomas. In the present study, PTEN was positively stained in the nucleus of corresponding noncancerous mucosa (Fig. 1A) or carcinoma cells (Fig. 1B) and infiltrating inflammatory cells. Whereas caspase-3 immuno- reactivity distributed to the cytoplasm of carcinoma cells (Fig. 1D). PTEN was positively detected in 325 of 327 (99.4\%) cases in corresponding non-cancerous mucosa. However, in some cancerous cases, no PTEN expression was detected (Fig. 1C). In total, 232 of 327 (70.9\%) cases positively expressed PTEN protein in colorectal carcinomas. PTEN expression in colorectal carcinoma was statistically lower than the adjacent non-cancerous mucosa $(\mathrm{P}<0.001)$ (Table II).

The relationship between the expression of PTEN and clinicopathological features of colorectal carcinoma. As Table III shows, PTEN expression was negatively correlated with tumor size, depth of invasion, lymphatic invasion, lymph node metastasis, lower Dukes staging, and lower caspase-3 expression $(\mathrm{P}<0.05)$, but not with patient age, differentiation and venous invasion $(\mathrm{P}>0.05)$. The male carcinoma patients exhibited stronger PTEN expression than females $(\mathrm{P}<0.05)$.

The amplification, sequencing and mutation analysis to exon 1,3-9 of PTEN in colorectal carcinoma. After DNA extraction, $\beta$-globin was evaluated as a control of DNA integrity and 57 samples displayed clear bands for the following PTEN amplification (Fig. 2). We did not detect exon 2 of PTEN despite changing primers twice. As summarized in Table IV, the amplification rate of PTEN exons 1 and 4 are $91.2 \%$ and $61.4 \%$, higher than the others. However, exons 8 and 9 displayed the lowest detection rate $(17.5 \%)$. Due to the weaker amplification of PCR, some samples were not sequenced although we repeated the experiments several times. Among these amplicon, only one synonymous mutation was found in exon 8 (codon 312 Asp: GAC $\rightarrow$ GAT) (Fig. 3).

Univariate and multivariate survival analysis. Follow-up information was available on 279 colorectal carcinoma patients for periods ranging from 0.9 months to 12.1 years (mean, 66.8 months). Univariate analysis using the KaplanMeier method suggested that the patients without PTEN expression had shorter survival than the patients with its expression ( $\mathrm{P}=0.003$ ) (Fig. 4). Multivariate analysis using Cox's proportional hazards model indicated that lymphatic invasion, venous invasion and PTEN expression were independent prognostic factors for overall colorectal carcinomas 
sense

GATAAGG

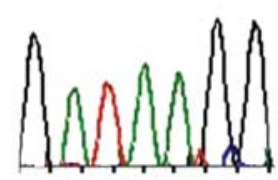

Asp

Tumor

sequence

Wild-Type

sequence antisense

C C T T A T C

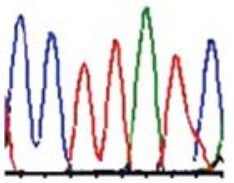

TTСССTТАТСTT

TTCCCTTGTCATT

\section{$\underbrace{}_{\text {Asp }}$}

Figure 3. PTEN mutation in colorectal carcinomas. The DNA sequencing analysis of case 39. Only one synonymous mutation (codon 312 $\mathrm{GAT} \rightarrow \mathrm{GAC}$ ) of exon 8 was noted.

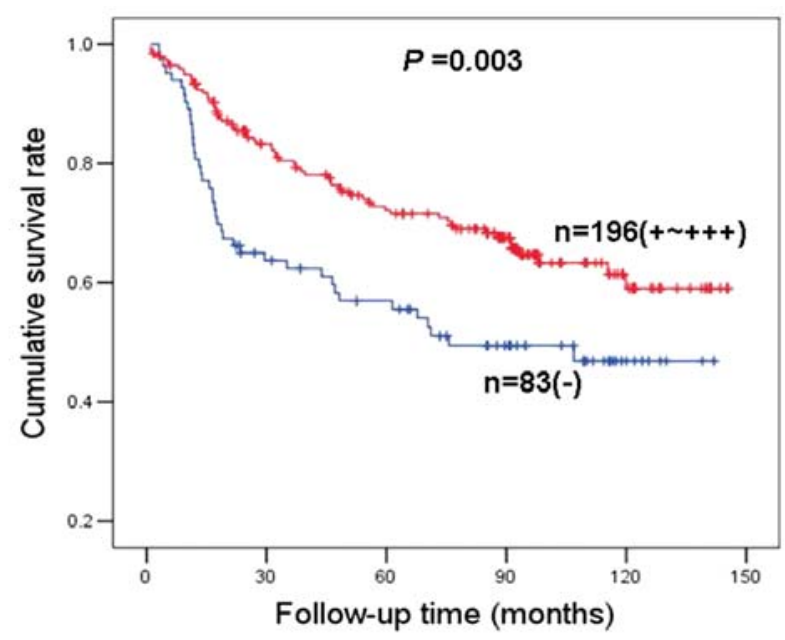

Figure 4. Correlation between the status of PTEN expression and prognosis of the patients with colorectal carcinomas. Kaplan-Meier curves for cumulative survival rate of patients according to the PTEN expression in all the colorectal carcinomas.
$(\mathrm{P}<0.05)$, but not age, gender, tumor size, depth of invasion, differentiation, lymph node metastasis or Dukes staging (Table V).

\section{Discussion}

PTEN, a tumor-suppressing gene, is involved in cellular differentiation, reproduction and apoptosis, as well as cellular adhesion and mobility and its loss or down-regulation plays an important role in the multiple steps of tumorigenesis and progression of malignancies (21). Enhanced tumorigenesis has also been observed in PTEN-deficient mice, which eventually develop loss of heterozygosity ( $\mathrm{LOH}$ ) of the remaining PTEN allele, leading to the appearance of tumors in the endometrium, liver, prostate, gastrointestinal tract, thyroid and thymus $(22,23)$. In the present study, we used the anti-PTEN antibody recognizing a 200 amino acid C-terminal region of PTEN molecule and found that it was localized in the nucleus of colonic epithelial and carcinoma cells as used previously $(1,2,24)$ although other investigators described cytoplasmic localization of PTEN protein using different antibodies (25-27). It was considered that the function of nuclear PTEN is not the same as cytoplasmic PTEN. Nuclear PTEN plays a role in chromosome stability, DNA repair, cell cycle arrest and cellular stability. It was postulated that simple diffusion, export dependent on a putative cytoplasmic localization signal, active shuttling by the RAN GTPase or major vault protein (MVP), phosphorylation-dependent shuttling and monoubiquitylationdependent import may be possible mechanisms for the nucleo-cytoplasmic shuttling of PTEN (28). Levels of nuclear PTEN may influence the cell cycle or the antiapoptotic activity of nucleophosmin (29-31). In our study, colorectal carcinomas displayed statistically lower PTEN expression than corresponding non-cancerous mucosa. The downregulated PTEN might be involved in the pathogenesis of colorectal carcinomas and be attributable to genetic or epigenetic changes, such as mutation, LOH, hypermethylation and microsatellite instability in various malignancies as described previously $(1,3)$.

Table V. Multivariate analysis of clinicopathological variables for survival with colorectal carcinomas.

\begin{tabular}{llr}
\hline Clinicopathological parameters & Relative risk $(95 \%$ CI) & P-value \\
\hline Age ( $\geq 65$ years) & $1.280(0.816-2.008)$ & 0.283 \\
Gender & $1.076(0.706-1.639)$ & 0.733 \\
Tumor size $(\geq 5 \mathrm{~cm})$ & $0.812(0.523-1.261)$ & 0.354 \\
Depth of invasion (into muscularis propria) & $3.020(0.378-24.152)$ & 0.468 \\
Differentiation (poor) & $1.144(0.795-1.647)$ & 0.297 \\
Lymphatic invasion $(+)$ & $1.613(1.024-2.540)$ & 0.039 \\
Venous invasion $(+)$ & $2.183(1.296-3.677)$ & 0.003 \\
Lymph node metastasis (+) & $1.769(0.731-4.283)$ & 0.206 \\
Dukes staging (C) & $1.672(0.799-3.498)$ & 0.172 \\
PTEN expression $(+\sim+++)$ & $0.653(0.432-0.986)$ & 0.042 \\
\hline
\end{tabular}

CI, confidence interval. 
Low expression of PTEN gene product was implicated in the clinicopathological stage and metastasis of various malignancies $(1,3)$. We found that decreased PTEN expression was closely linked to tumor size, invasive depth, lymph node metastasis, and higher Dukes staging of colorectal carcinomas, similar to a previous report (32). Furthermore, univariate analysis showed that the patients without PTEN expression showed poorer prognosis than the patiens with its expression. Multivariate analysis indicated that PTEN expression and lymphatic invasion, venous invasion were independent prognostic factors for overall colorectal carcinomas. It was suggested that down-regulated expression of the PTEN protein probably contributed to growth, invasion, and metastasis of colorectal carcinoma and could be considered as a good marker to indicate the aggressive behaviors and poor prognosis of colorectal carcinomas. Several putative mechanisms relating to tumor suppression of PTEN have been reported such as inhibiting cell mobility and facilitating cell adhesion by dephosphorating FAK, inhibiting cell apoptosis and increasing cell growth by dephosphorating PIP3 and restraining cell differentiation by inhibiting MAPK signal pathway. Abnormal expression of the PTEN protein was involved in progression of colorectal carcinoma by its effects on cell mobility, adhesion, apoptosis, growth and differentiation $(1,3,21)$.

As a negative regulator of the conserved insulin/IGFPI3K signaling pathway, conditional deletion of PTEN caused increased proliferation, decreased apoptosis and tumorigenesis. PTEN's promotion of the apoptotic response may cooperate with its function in cell cycle arrest, and may be mediated by more than one mechanism $(28,29)$. Caspase- 3 is an apoptosis related enzyme and ultimately execute apoptotic cell death. Active caspase- 3 consists of large and small subunits, which are released from the procaspase through proteolytic processing, plays a key role in apoptosis $(32,33)$. Schwartzbauer et al (34) found increased PTEN expression by recombinant adenovirus in cultured neonatal rat primary cardiomyocytes caused cardiomyocyte apoptosis as evidenced by increased caspase-3 activity and cleaved poly(A) DP-ribose polymerase. Here, the PTEN expression was positively correlated with caspase- 3 expression in colorectal carcinomas. Consequently, we could infer that low expression of PTEN decreased expression of caspase- 3 to cause tumor cells apoptosis dysfunction, which is the theoretic basis of contribution of PTEN to tumorigenesis and progression of colorectal carcinomas.

Since germline mutations of the PTEN gene are found in two hamartoma disorders called Cowden syndrome and Bannayan-Riley-Ruvalcaba syndrome, different types of mutations in the PTEN locus such as frameshifts, missense mutations, and splicing variants were found to be associated with a broad range of human cancers (35-37). These mutations sometimes induce early termination of the translation and subsequently cause the production of unstable messages and/ or immature gene products, which are no longer able to form functional phosphatase domain and completely lose the phosphatase activity, but most of missense mutations results in robust decrease in the phosphatase activity (38-40). Although some reports showed 17\%-19.5\% mutation of PTEN $(15,25)$, in our study, only one synonymous mutation was detected in
PTEN exon 8 (codon 312 Asp: GAC $\rightarrow$ GAT). To improve the accuracy of the PCR amplification and sequence, we employed the high-fidelity PfuUltra ${ }^{\mathrm{TM}}$ polymerase in PCR reaction mixture and sequenced each amplicon from both ends although some samples were not yet available for the direct sequencing. Additionally, we carefully analyzed the starting and ending data of DNA sequence because of its instability. It was also reported that PTEN expression was frequently diminished at the transcriptional/translational level. DNA methylation, transcriptional repression and microRNA-directed mRNA degradation and translational disruption appear to reduce PTEN expression in some cancers $(41,42)$. Therefore, it might be concluded that mutation of PTEN was not common in Japanese colorectal carcinomas.

In summary, the study suggested that down-regulated PTEN expression was involved in pathogenesis, invasion and metastasis of colorectal carcinomas possibly by regulating the balance between apoptosis and proliferation. PTEN expression may be a good marker for prognosis of colorectal carcinoma.

\section{Acknowledgements}

We particularly thank Tokimasa Kumada and Hideki Hatta for their technical help. This study was supported by Shenyang Outstanding Talent Foundation of China, Liaoning BaiQianWan Talents Program, Grant-in-Aid for Scientific Research from the Ministry of Education, Culture, Sports and Technology of Japan (20659109), and Smoking Research Foundation.

\section{References}

1. Zheng H, Takahashi H, Murai Y, Cui Z, Nomoto K, Tsuneyama K and Takano Y: Low expression of FHIT and PTEN correlates with malignancy of gastric carcinomas: tissue-array findings. Appl Immunohistochem Mol Morphol 15: 432-440, 2007.

2. Zheng H, Tsuneyama K, Takahashi H, Miwa S, Nomoto K, Saito H, Masuda S and Takano Y: Expression of PTEN and FHIT is involved in regulating the balance between apoptosis and proliferation in lung carcinomas. Anticancer Res 27: 575-581, 2007.

3. Zheng HC, Sun JM, Li XH, Yang XF, Zhang YC and Xin Y: Role of PTEN and MMP-7 expression in growth, invasion, metastasis and angiogenesis of gastric carcinoma. Pathol Int 53: 659-666, 2003 .

4. Jones RG, Elford AR, Parsons MJ, Wu L, Krawczyk CM, Yeh WC, Hakem R, Rottapel R, Woodgett JR and Ohashi PS: CD28-dependent activation of protein kinase B/Akt blocks Fas-mediated apoptosis by preventing death-inducing signaling complex assembly. J Exp Med 196: 335-348, 2002.

5. Keniry M and Parsons R: The role of PTEN signaling perturbations in cancer and in targeted therapy. Oncogene 27: 5477-5485, 2008 .

6. Liaw D, Marsh DJ, Li J, Dahia PL, Wang SI, Zheng Z, Bose S, Call KM, Tsou HC, Peacocke M, Eng C and Parsons R: Germline mutations of the PTEN gene in Cowden disease, an inherited breast and thyroid cancer syndrome. Nat Genet 16: 64-67, 1997.

7. Marsh DJ, Dahia PL, Zheng Z, Liaw D, Parsons R, Gorlin RJ and Eng C: Germline mutations in PTEN are present in Bannayan-Zonana syndrome. Nat Genet 16: 333-334, 1997.

8.Zhou XP, Marsh DJ, Hampel H, Mulliken JB, Gimm O and Eng C: Germline and germline mosaic PTEN mutations associated with a Proteus-like syndrome of hemihypertrophy, lower limb asymmetry, arteriovenous malformations and lipomatosis. Hum Mol Genet 9: 765-768, 2000.

9. Zhou X, Hampel H, Thiele H, Gorlin RJ, Hennekam RC, Parisi M, Winter RM and Eng C: Association of germline mutation in the PTEN tumour suppressor gene and Proteus and Proteus-like syndromes. Lancet 358: 210-211, 2001. 
10. Li J, Yen C, Liaw D, Podsypanina K, Bose S, Wang SI, Puc J, Miliaresis C, Rodgers L, McCombie R, Bigner SH, Giovanella BC, Ittmann M, Tycko B, Hibshoosh H, Wigler MH and Parsons R: PTEN, a putative protein tyrosine phosphatase gene mutated in human brain, breast, and prostate cancer. Science 275: 1943-1947, 1997.

11. Steck PA, Pershouse MA, Jasser SA, Yung WK, Lin H, Ligon AH, Langford LA, Baumgard ML, Hattier T, Davis T, Frye C, Hu R, Swedlund B, Teng DH and Tavtigian SV: Identification of a candidate tumour suppressor gene, MMAC1, at chromosome 10q23.3 that is mutated in multiple advanced cancers. Nat Genet 15: 356-362, 1997.

12. Georgescu MM, Kirsch KH, Kaloudis P, Yang H, Pavletich NP and Hanafusa H: Stabilization and productive positioning roles of the C2 domain of PTEN tumor suppressor. Cancer Res 60: 7033-7038, 2000.

13. Bose S, Wang SI, Terry MB, Hibshoosh $\mathrm{H}$ and Parsons R: Allelic loss of chromosome 10q23 is associated with tumor progression in breast carcinomas. Oncogene 17: 123-127, 1998.

14. Feilotter HE, Nagai MA, Boag AH, Eng C and Mulligan LM: Analysis of PTEN and the 10q23 region in primary prostate carcinomas. Oncogene 16: 1743-1748, 1998.

15. Dicuonzo G, Angeletti S, Garcia-Foncillas J, Brugarolas A, Okrouzhnov Y, Santini D, Tonini G, Lorino G, De Cesaris M and Baldi A: Colorectal carcinomas and PTEN/MMAC1 gene mutations. Clin Cancer Res 7: 4049-4053, 2001.

16. Lin WM, Forgacs E, Warshal DP, Yeh IT, Martin JS, Ashfaq R and Muller CY: Loss of heterozygosity and mutational analysis of the PTEN/MMAC1 gene in synchronous endometrial and ovarian carcinomas. Clin Cancer Res 4: 2577-2583, 1998.

17. Boyle $\mathrm{P}$ and Leon ME: Epidemiology of colorectal cancer. $\mathrm{Br}$ Med Bull 64: 1-25, 2002.

18. Zheng H, Tsuneyama K, Cheng C, Takahashi H, Cui Z, Murai Y, Nomoto $\mathrm{K}$ and Takano $\mathrm{Y}$ : Maspin expression was involved in colorectal adenoma-adenocarcinoma sequence and liver metastasis of tumors. Anticancer Res 27: 259-265, 2007.

19. Zinkin LD: A critical review of the classifications and staging of colorectal cancer. Dis Colon Rectum 26: 37-43, 1983.

20. Kumada T, Tsuneyama $K$, Hatta $H$, Ishizawa $S$ and Takano $Y$ : Improved 1-h rapid immunostaining method using intermittent microwave irradiation: practicability based on 5 years application in Toyama Medical and Pharmaceutical University Hospital. Mod Pathol 17: 1141-1149, 2004.

21. Parsons R: Human cancer, PTEN and the PI-3 kinase pathway. Semin Cell Dev Biol 15: 171-176, 2004.

22. Di Cristofano A, Pesce B, Cordon-Cardo C and Pandolfi PP: Pten is essential for embryonic development and tumour suppression. Nat Genet 19: 348-355, 1998

23. Podsypanina K, Ellenson LH, Nemes A, Gu J, Tamura M, Yamada KM, Cordon-Cardo C, Catoretti G, Fisher PE and Parsons R: Mutation of Pten/Mmac1 in mice causes neoplasia in multiple organ systems. Proc Natl Acad Sci USA 96: 1563-1568, 1999.

24. Zheng H, Tsuneyama K, Cheng C, Takahashi H, Cui Z, Nomoto K, Murai Y and Takano Y: Expression of KAI1 and tenascin, and microvessel density are closely correlated with liver metastasis of gastrointestinal adenocarcinoma. Clin Pathol 60: 50-56, 2007.

25. Nassif NT, Lobo GP, Wu X, Henderson CJ, Morrison CD, Eng C, Jalaludin B and Segelov E: PTEN mutations are common in sporadic microsatellite stable colorectal cancer. Oncogene 23: 617-628, 2004.

26. Taniyama K, Goodison S, Ito R, Bookstein R, Miyoshi N, Tahara E, Tarin D and Urquidi V: PTEN expression is maintained in sporadic colorectal tumours. J Pathol 194: 341-348, 2001.
27. Zhou XP, Loukola A, Salovaara R, Nystrom-Lahti M, Peltomaki P, de la Chapelle A, Aaltonen LA and Eng C: PTEN mutational spectra, expression levels, and subcellular localization in microsatellite stable and unstable colorectal cancers. Am J Pathol 161: 439-447, 2002.

28. Planchon SM, Waite KA and Eng C: The nuclear affairs of PTEN. J Cell Sci 121: 249-253, 2008.

29. Liu JL, Mao Z, LaFortune TA, Alonso MM, Gallick GE, Fueyo J and Yung WK: Cell cycle-dependent nuclear export of phosphatase and tensin homologue tumor suppressor is regulated by the phosphoinositide-3-kinase signaling cascade. Cancer Res 67: 11054-11063, 2007.

30. Martelli AM, Cocco L, Capitani S, Miscia S, Papa S and Manzoli FA: Nuclear phosphatidylinositol 3,4,5-trisphosphate, phosphatidylinositol 3-kinase, Akt, and PTen: emerging key regulators of anti-apoptotic signaling and carcinogenesis. Eur J Histochem 51 (Suppl. 1): 125-131, 2007.

31. Gil A, Andrés-Pons A, Fernández E, Valiente M, Torres J, Cervera J and Pulido R: Nuclear localization of PTEN by a Randependent mechanism enhances apoptosis: involvement of an N-terminal nuclear localization domain and multiple nuclear exclusion motifs. Mol Biol Cell 17: 4002-4013, 2006.

32. Chow LM and Baker SJ: PTEN function in normal and neoplastic growth. Cancer Lett 241: 184-196, 2006.

33. De Oca J, Azuara D, Sanchez-Santos R, Navarro M, Capella G, Moreno V, Sola A, Hotter G, Biondo S, Osorio A, Martí-Ragué J and Rafecas A: Caspase- 3 activity, response to chemotherapy and clinical outcome in patients with colon cancer. Int $\mathrm{J}$ Colorectal Dis 23: 21-27, 2008.

34. Schwartzbauer G and Robbins J: The tumor suppressor gene PTEN can regulate cardiac hypertrophy and survival. J Biol Chem 276: 35786-35793, 2001

35. Kim DK, Myung SJ, Yang SK, Hong SS, Kim KJ, Byeon JS, Lee GH, Kim JH, Min YI, Lee SM, Jeong JY, Song K and Jung SA: Analysis of PTEN gene mutations in Korean patients with Cowden syndrome and polyposis syndrome. Dis Colon Rectum 48: 1714-1722, 2005.

36. Wang JY, Huang TJ, Chen FM, Hsieh MC, Lin SR, Hou MF and Hsieh JS: Mutation analysis of the putative tumor suppressor gene PTEN/MMAC1 in advanced gastric carcinomas. Virchows Arch 442: 437-443, 2003.

37. Tate G, Suzuki T and Mitsuya T: Mutation of the PTEN gene in a human hepatic angiosarcoma. Cancer Genet Cytogenet 178: $160-162,2007$.

38. Furnari FB, Huang HJ and Cavenee WK: The phosphoinositol phosphatase activity of PTEN mediates a serum-sensitive G1 growth arrest in glioma cells. Cancer Res 58: 5002-5008, 1998.

39. Han SY, Kato H, Kato S, Suzuki T, Shibata H, Ishii S, Shiiba K, Matsuno S, Kanamaru R and Ishioka C: Functional evaluation of PTEN missense mutations using in vitro phosphoinositide phosphatase assay. Cancer Res 60: 3147-3151, 2000

40. Koul D, Jasser SA, Lu Y, Davies MA, Shen R, Shi Y, Mills GB and Yung WK: Motif analysis of the tumor suppressor gene MMAC/PTEN identifies tyrosines critical for tumor suppression and lipid phosphatase activity. Oncogene 21: 2357-2364, 2002.

41. Wiencke JK, Zheng S, Jelluma N, Tihan T, Vandenberg S, Tamgüney T, Baumber R, Parsons R, Lamborn KR, Berger MS, Wrensch MR, Haas-Kogan DA and Stokoe D: Methylation of the PTEN promoter defines low-grade gliomas and secondary glioblastoma. Neuro Oncol 9: 271-279, 2007.

42. Yang H, Kong W, He L, Zhao JJ, O'Donnell JD, Wang J, Wenham RM, Coppola D, Kruk PA, Nicosia SV and Cheng JQ: MicroRNA expression profiling in human ovarian cancer: miR214 induces cell survival and cisplatin resistance by targeting PTEN. Cancer Res 68: 425-433, 2008. 